\title{
Commentary to: “Morphologic changes after bladder neck intussusception in laparoscopic radical prostatectomy contribute to early postoperative continence"
}

\author{
Daniel J. Culkin ${ }^{1}$
}

Received: 24 February 2019 / Accepted: 26 February 2019 / Published online: 8 April 2019

C) Springer Nature B.V. 2019

The authors are to be congratulated on their diligence in the evaluation of the anatomical changes, the subjective and objective parameters of lower urinary tract symptoms, and the continence rates after laparoscopic radical prostatectomies comparing a technique with or without a bladder neck intussusception. The design was that of a prospective "nonrandomized" trial of the bladder neck intussusception to improve continence rates as well as time to continence. The results indicate that both time to continence and continence rates were dramatically better with the bladder neck procedure. Perhaps one of the most significant problems regarding quality of life is the occurrence of urinary incontinence and LUTS post prostatectomy. This represents a potential to improve the quality of life of these patient. However, these results are preliminary and beg the need for a well-designed prospective randomized clinical trial to validate these early questions.

Publisher's Note Springer Nature remains neutral with regard to jurisdictional claims in published maps and institutional affiliations.

This comment refers to the article available online at https://doi. org/10.1007/s11255-019-02118-0.

Daniel J. Culkin

Daniel-Culkin@ouhsc.edu

1 University of Oklahoma Health Sciences Center,

Oklahoma City, OK, USA 